\title{
Avaliação do potencial mutagênico de cobre da água do rio Uruguai
}

\author{
Evaluating the copper water uruguay river mutagenic potential
}

\author{
Leonardo Munhoz Benites ${ }^{1}$, Kennia Brum Doncato ${ }^{2}$, Thais dos Santos Minho ${ }^{3}$, \\ Giselle Xavier Perazzo ${ }^{4}$ \\ 1,2,3,4 Universidade Federal do Pampa, RS, Brasil
}

\begin{abstract}
Resumo
Análises da água do rio Uruguai constataram a presença de compostos em concentrações acima dos limites recomendados pela legislação brasileira, a exemplo do cobre. Diante disso, o presente estudo objetivou avaliar o potencial mutagênico do cobre, realizando a exposição da espécie bioindicadora Danio rerio ao metal em sistemas de bioensaio. Após período de aclimatação, trinta e seis animais foram separados em três grupos, com tréplicas: (a) Controle (sem adição de cobre), (b) T1 (com 0,08 mg/L-concentração observada no rio) e (c) T2 (com 0,009 mg/L - concentração recomendada pelo CONAMA). Decorrido 120 horas de exposição, procedeu-se a coleta de sangue para o Teste de Micronúcleo Písceo, onde foram analisadas 2000 células por indivíduo, sendo o resultado analisado estatisticamente pelo teste de Kruskal-Wallis. Foram observadas diferenças altamente significativas $(p<0,01)$ entre os três grupos de estudo, sendo maior a frequência de micronúcleos em T1 quando comparado com o controle $(p=0,0079)$ e T2 $(p=0,0027)$. Dessa forma, o presente estudo aponta possíveis consequências da contaminação por cobre para a ictiofauna local desse importante recurso hídrico, utilizado tanto como fonte de água para vários municípios como para pesca extrativa.
\end{abstract}

Palavras-chave: ecotoxicologia. micronúcleo. poluição. zebrafish.

\begin{abstract}
Analysis of Uruguay river water noted the presence of compounds at concentrations above the limits recommended by the brazilian legislation, such as the copper. Therefore, this study aimed to evaluate the mutagenic potential of copper conducting exposure of bioindicator species Danio rerio to the metal in bioassay systems. After acclimation period, thirty-six animals were divided into three groups, with rejoinders: (a) Control (without copper), (b) T1 (with $0.08 \mathrm{mg} / \mathrm{L}$ - concentration observed in the river) and (c) T2 (with $0.009 \mathrm{mg} / \mathrm{L}$ - concentration recommended by CONAMA). After 120 hours of exposure, we proceeded to collect blood for the piscine micronucleus test, where 2000 cells were analyzed per individual, the result being statistically analyzed using the Kruskal-Wallis test. Were observed highly significant differences $(p<0.01)$ among the three study groups, with a higher frequency of micronuclei in T1 compared with the control $(p=0.0079)$ and T2 $(p=0.0027)$. Thus, this study suggests possible consequences of copper contamination to the local fish fauna of this important water resource, used both as a source of water to several municipalities and for extractive fishing.
\end{abstract}

Keywords: ecotoxicology. micronuclei. poluttion. zebrafish. Recebido: 24/04/2014 Aceito: 24/05/2014 


\section{Introdução}

A bacia do rio Uruguai é uma das doze regiões hidrográficas do território brasileiro e possui aproximadamente $371.000 \mathrm{~km}^{2}$, sendo $45 \%$ situado no país, especificamente nos estados do Rio Grande do Sul e de Santa Catarina (ANA, 2011a). Essa região hidrográfica apresenta grande importância em função das atividades agroindustriais desenvolvidas e pelo seu potencial hidrelétrico, devendose ressaltar ainda a utilização deste recurso hídrico para geração de renda para pescadores da região.

Porém, apesar de contribuírem para o desenvolvimento econômico da região, muitas das atividades realizadas nesta bacia hidrográfica acabam agravando a contaminação das suas águas, conforme representado na Figura 1. Arins (2010) cita que, dentre os impactos causados, destacam-se o despejo inadequado de esgotos domésticos e a utilização de agrotóxicos nas lavouras agrícolas, principalmente na rizicultura.

Tal problema de contaminação hídrica pode ser verificado através da análise realizada pela Agência Nacional de Águas (ANA, 2011b), a qual constatou que o rio Uruguai apresenta níveis de poluição consideravelmente altos, frente às recomendações da resolução 357 do Conselho Nacional do Meio Ambiente - CONAMA (MMA, 2005). Alguns compostos apresentaram concentrações elevadas em coletas de água junto ao município de Uru- guaiana, no Rio Grande do Sul, como, por exemplo, o fósforo, que apresentou $0,27 \mathrm{mg} / \mathrm{L}$, sendo o recomendado pela ANA $(2011 \mathrm{~b})$ de $0,1 \mathrm{mg} / \mathrm{L}$, o alumínio $(51,3 \mathrm{mg} / \mathrm{L}$; recomendado: $0,1 \mathrm{mg} / \mathrm{L})$, o cromo $(0,07 \mathrm{mg} / \mathrm{L}$; recomendado: $0,05 \mathrm{mg} / \mathrm{L})$, o ferro $(43,16 \mathrm{mg} / \mathrm{L}$; recomendado: $0,3 \mathrm{mg} / \mathrm{L})$ e o cobre $(0,08 \mathrm{mg} / \mathrm{L}$; recomendado: $0,009 \mathrm{mg} / \mathrm{L})$; sendo este último o contaminante de estudo neste trabalho.

O cobre pertence ao grupo dos metais pesados, que são severos poluentes de solo e de água devido à frequente utilização destes nas atividades agrícolas, estando presentes em diversos produtos, incluindo agrotóxicos. Além disso, estes compostos podem ser absorvidos e armazenados no organismo de animais, inclusive naqueles utilizados para consumo humano, a exemplo do peixe, o que acaba intoxicando-os e colocando em risco a saúde das pessoas que vierem a se alimentar de sua carne. Conforme Muller (2008), quando absorvidos pelo ser humano, estes elementos se depositam no tecido ósseo e gorduroso e deslocam minerais nobres dos ossos e músculos para a circulação, podendo provocar sérias doenças.

Devido a isso, surge a importância da realização de estudos ecotoxicológicos, os quais buscam analisar os efeitos adversos de poluentes exógenos, ao ambiente, sobre os organismos aquáticos (LOMBARDI et. al., 2004). Tais estudos podem ser conduzidos diretamente no ambiente ou através de bioensaios (testes experimentais

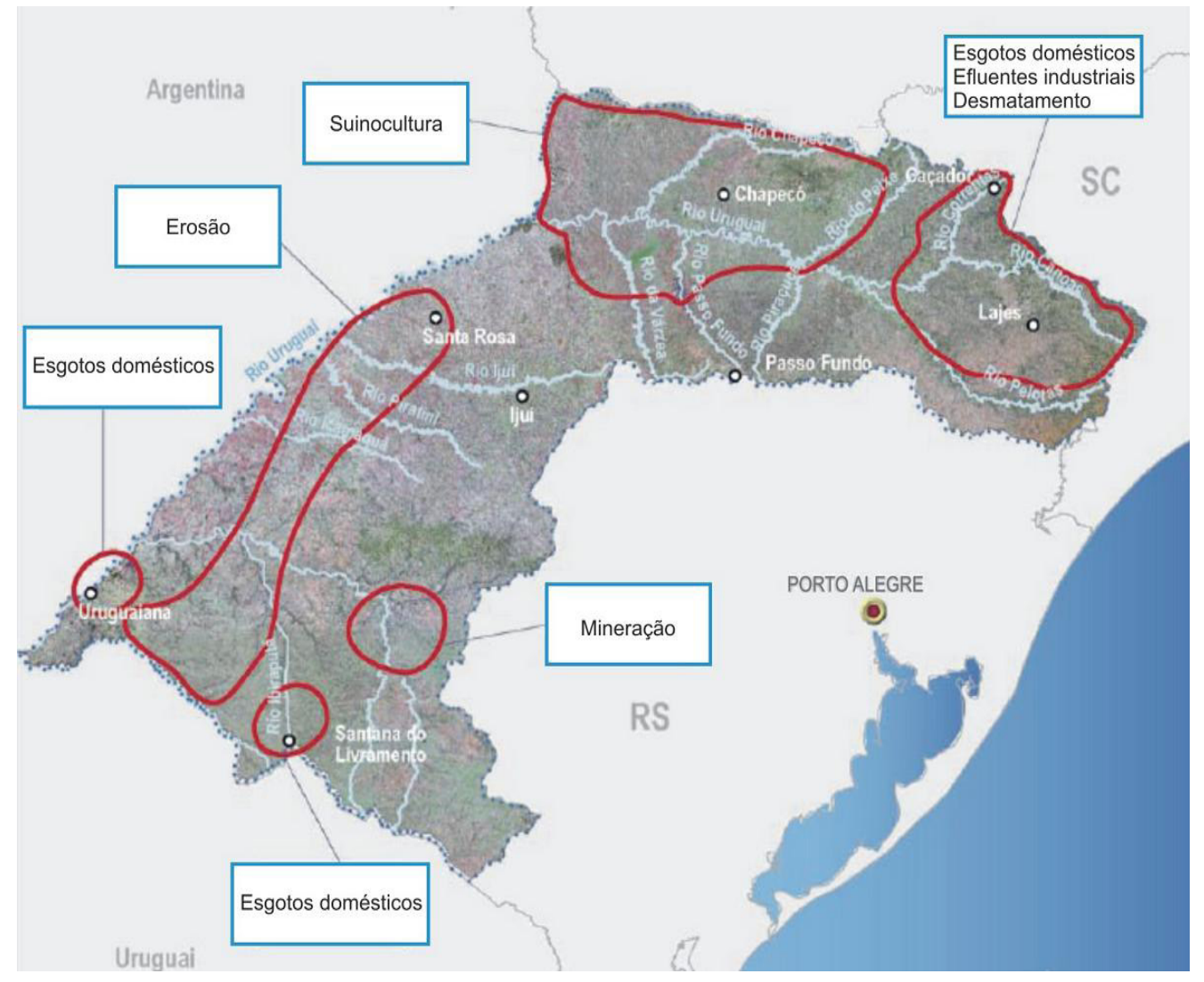

Figura 1 - Principais áreas críticas de contaminação da bacia do rio Uruguai, em território brasileiro. Fonte: Adaptado de ANA (2005) 


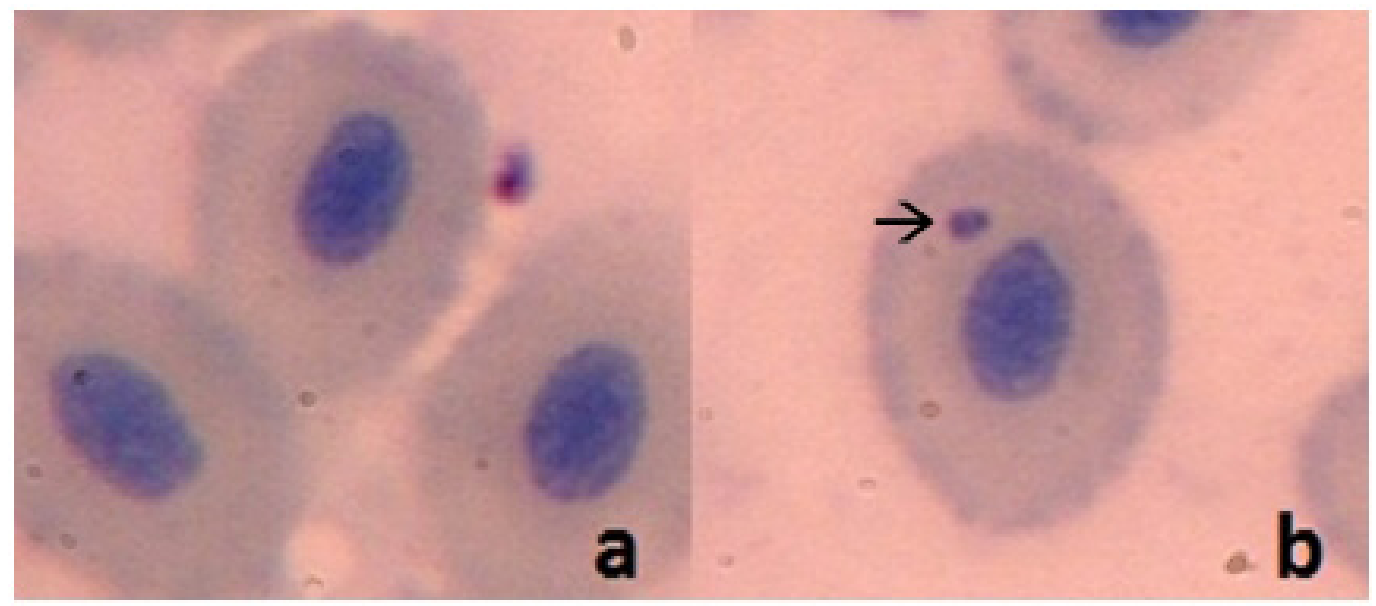

Figura 2 - Eritrócitos de D. rerio, com representação das células normais (a) em comparação à célula danificada com micronúcleo (b), no aumento aproximado de 1000x.

de metodologias distintas), existindo, inclusive, normas quanto à utilização de organismos bioindicadores em testes deste tipo. No caso dos peixes, a espécie Danio rerio está entre as consideradas como padrão de referência internacional, devido a inúmeras características como o sequenciamento completo do seu genoma, que se assemelha aos demais vertebrados, incluindo os seres humanos (OLIVEIRA, 2009). Os bioindicadores são utilizados para avaliar os níveis de poluição devido às respostas obtidas quando estes são expostos a diversos tipos de poluentes; sendo que essas respostas podem ser bioquímicas, fisiológicas e histológicas, as quais são conhecidas como biomarcadores. Até mesmo os biomarcadores de análise de mutagenicidade podem ser realizados com a utilização de bioindicadores (MONSERRAT et. al., 2001), sendo este o foco do presente trabalho.

Dentre as análises mutagênicas mais comuns, realizadas com organismos aquáticos, pode-se destacar, entre outras, o teste do Micronúcleo Písceo, realizado originalmente por Hooftman \& Raat (1982), conforme adaptação do teste anteriormente empregado por Schmid (1975) em mamíferos. O micronúcleo (figura 2) é semelhante ao núcleo em forma, estrutura e propriedades de coloração, podendo variar grandemente em tamanho, sendo que sua formação pode ser induzida durante o processo de divisão celular por agentes que danificam diretamente o cromossomo, produzindo quebras, ou por agentes que afetam o fuso mitótico (MALUF \& ERDTMANN, 2003). Esses fragmentos ou cromossomos inteiros não são capazes de se orientar para os núcleos filhos da célula em divisão, ficando perdidos no citoplasma, de modo que acabam formando uma membrana nuclear própria, originando assim os micronúcleos (HEDDLE et. al., 1983). El-Shahaby et. al. (2003) citam que esta técnica permite a análise de um grande número de células, sendo assim uma ferramenta simples e precisa de se estimar dano genético celular induzido por compostos químicos.

Assim, tendo em vista a situação em que se encontra o rio Uruguai e a alta toxicidade que possuem os diferentes metais presentes em suas águas, o presente trabalho objetivou avaliar os possíveis danos genéticos da exposição de diferentes concentrações de cobre em exemplares de D. rerio, em sistemas de bioensaios, através do emprego do Teste do Micronúcleo Písceo. Dessa forma, buscouse verificar o potencial mutagênico das concentrações de $0,08 \mathrm{mg} / \mathrm{L}$ de cobre encontrada no rio Uruguai e de 0,009mg/L de cobre recomendada como limite máximo pelo CONAMA, bem como testar o período de $120 \mathrm{~h}$ de exposição ao contaminante para danos genéticos dos exemplares, avaliar o potencial bioindicador de $D$. rerio em relação as concentrações de cobre avaliadas e realizar uma avaliação preliminar do risco genotóxico do cobre para os peixes da bacia do rio Uruguai.

\section{Material e método}

Este estudo foi realizado no Laboratório de Aquariofilia, da Universidade Federal do Pampa, Campus Uruguaiana, sendo utilizados 36 exemplares de zebrafish (D. rerio), de origem comercial, com média de $4,277 \pm 0,31 \mathrm{~cm}$ de comprimento. Os peixes foram mantidos em número de quatro exemplares para cada recipiente de 20 litros por um período de doze dias para aclimatação. Os recipientes possuíam sistemas de aeração constante, de modo que durante a aclimatação foi fornecida aos animais ração comercial Anhambi ${ }^{\oplus,}$ com $40 \%$ de proteína, oferecida na proporção de $3 \%$ do peso vivo, duas vezes ao dia; sendo esta diminuída gradativamente durante os dois últimos dias antes do bioensaio para evitar o cessamento brusco da alimentação. Durante a aclimatação, foram feitas medições diárias dos principais parâmetros físico-químicos: temperatura, salinidade, condutividade, oxigênio dissolvido e potencial hidrogeniônico da água, cujos valores estão na tabela 1 ; além de alcalinidade, que se manteve entre 180 e $240 \mathrm{mg} / \mathrm{L}$, e amônia, estável em 1,0 mg/L. Além disso, realizou-se trocas parciais de 1/3 
Tabela 1 - Valores médios dos parâmetros físico-químicos da água durante o período de aclimatação

\begin{tabular}{cc}
\hline Parâmetro & Média \\
\hline Temperatura $\left({ }^{\circ} \mathrm{C}\right)$ & $19,78 \pm 1,39$ \\
$\mathrm{pH}$ & $9,15 \pm 0,75$ \\
Oxigênio Dissolvido $(\mathrm{mg} / \mathrm{L})$ & $5,86 \pm 0,52$ \\
Condutividade $(\mathrm{mS} / \mathrm{cm})$ & $0,562 \pm 0,007$ \\
Salinidade $(\mathrm{PSU})$ & $0,27 \pm 0,005$ \\
\hline
\end{tabular}

da água a cada três dias, para evitar problemas com a qualidade da água.

Decorrido esse período de aclimatação, os espécimes foram separados em três grupos experimentais, sendo (a) grupo controle (sem adição de contaminante), (b) tratamento 1 (T1), onde foi feita a exposição dos exemplares à concentração $0,08 \mathrm{mg} / \mathrm{L}$ de cobre (encontrada no rio Uruguai), e (c) tratamento 2 (T2), onde foi utilizada a concentração de $0,009 \mathrm{mg} / \mathrm{L}$ (limite recomendado pelo CONAMA); sendo feitas três repetições por tratamento. $\mathrm{O}$ contaminante esteve sob a forma de sulfato de cobre $\left(\mathrm{CuSO}_{2} \cdot 5 \mathrm{H}_{2} \mathrm{O}\right)$, sendo este um composto comumente encontrado na composição de muitos agrotóxicos utilizados nas lavouras.

A exposição dos zebrafish às diferentes concentrações do metal pesado ocorreu durante $120 \mathrm{~h}$, onde cessou-se qualquer manejo nos recipientes, inclusive a oferta de alimento. Após esse tempo, os animais foram eutanasiados e os tecidos sanguíneos coletados submetidos ao teste do Micronúcleo Písceo, conforme a técnica empregada por Carrasco et al. (1990), a qual considera a contagem de 2000 células por espécime. Para a análise estatística dos resultados, foi utilizado o teste de Kruskal-Wallis $(p=0,05)$, executado no programa Bioestat 5.0.

\section{Resultados e Discussão}

Em relação ao teste mutagênico, os resultados encontrados demonstraram a presença de danos genéticos do tipo micronúcleo, além de outras anormalidades morfológicas nos eritrócitos. A Tabela 2 representa a quantidade destas alterações em cada tratamento, com suas respectivas médias, sendo consideradas 2000 células por cada animal analisado.

As análises dos eritrócitos demonstraram diferença significativa quanto à presença de micronúcleos nos diferentes grupos do experimento $(p=0,0014)$, sendo que T1 apresentou maior frequência desta alteração quando comparado com o grupo controle $(\mathrm{p}=0,0032)$

Tabela 2 - Quantidade de micronúcleos e alterações dos animais de cada tratamento

\begin{tabular}{c|cc|ccc}
\hline $\begin{array}{c}\text { Quantidade } \\
\text { de } \\
\text { micronúcleos }\end{array}$ & \multicolumn{5}{|c}{ Quantidade de alterações } \\
\hline Controle & $\mathrm{T} 1$ & $\mathrm{~T} 2$ & Controle & $\mathrm{T} 1$ & $\mathrm{~T} 2$ \\
\hline 2 & 4 & 6 & 13 & 54 & 13 \\
3 & 8 & 5 & 18 & 26 & 40 \\
2 & 3 & 3 & 29 & 53 & 30 \\
1 & 13 & 1 & 24 & 39 & 32 \\
5 & 4 & 1 & 19 & 70 & 30 \\
1 & 8 & 2 & 24 & 19 & 13 \\
1 & 8 & 1 & 41 & 25 & 26 \\
2 & 8 & 1 & 21 & 35 & 34 \\
5 & 6 & 2 & 36 & 54 & 36 \\
3 & 5 & 2 & 12 & 29 & 32 \\
9 & 5 & 3 & 23 & 16 & 12 \\
2 & 2 & 2 & 49 & 11 & 13 \\
\hline $3,00^{*}$ & $6,16^{*}$ & $2,41^{*}$ & $25,75^{*}$ & $35,91^{*}$ & $25,91^{*}$ \\
\hline
\end{tabular}

*quantidade média em cada tratamento 


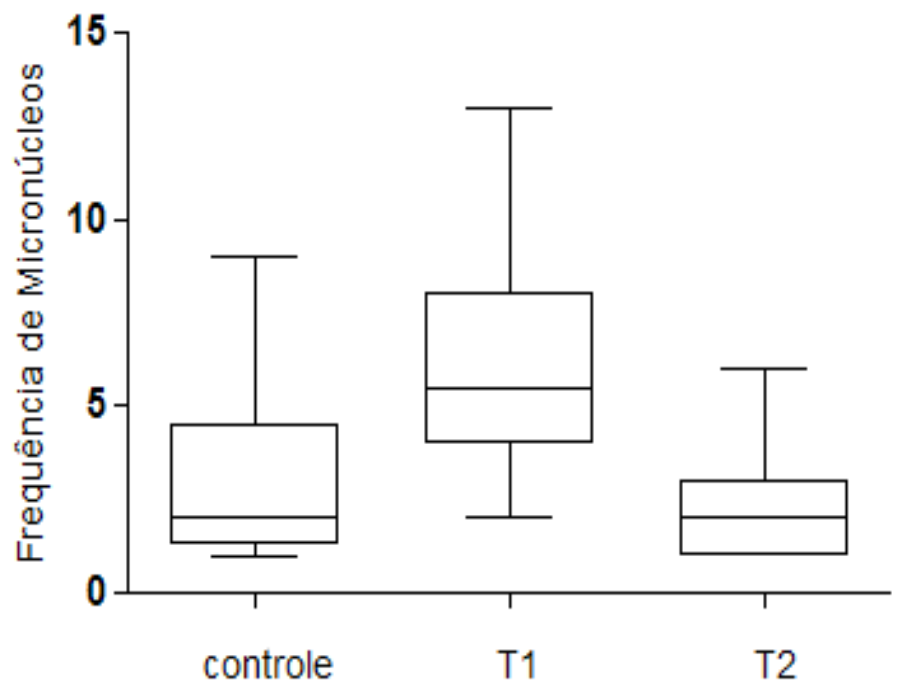

Figura 3 - Frequência média de danos do tipo micronúcleo encontrada nos tratamentos

e com T2 ( $\mathrm{p}=0,0013)$, não sendo observadas diferenças entre controle e T2 ( $\mathrm{p}=0$,7862) (Figura 3). Como visto, também foram analisadas todas as alterações nucleares, conforme descrito por Carrasco et al. (1990), não sendo observadas diferenças significativas entre os grupos $(\mathrm{p}>0,05)$.

Resultados semelhantes foram encontrados por Galvan et. al. (2012), que observaram maior frequência de micronúcleos em eritrócitos de Astyanax altiparanae quando expostos a uma concentração de $0,125 \mathrm{mg} / \mathrm{L}$ de sulfato de cobre por um período de $72 \mathrm{~h}$. Porém nesta mesma pesquisa a espécie $A$. serratus não demonstrou diferença estatística nessas mesmas condições quando em comparação ao grupo controle, assim como observado por Marques (2011) com A. fasciatus a 0,013 mg/L de cobre durante 168h; desta forma verifica-se que o potencial bioindicador varia dependendo da espécie utilizada. Por sua vez, Piancini et. al. (2012) verificaram que o cobre causa danos no DNA de hemácias de peixes em concentrações extremamente baixas, seu estudo indicou frequências de alterações estatisticamente maiores em Rhamdia quelen expostos em $96 \mathrm{~h}$ a $0,018 \mathrm{mg} / \mathrm{L}$ de cloreto cobre em relação ao grupo controle e ao tratamento com 0,009mg/L deste contaminante, resultados semelhantes aos observados neste artigo.

Al-Sabti \& Metcalfe (1995) destacam que ensaios utilizando peixes como organismo modelo incluem a facilidade com a qual teleósteos, especialmente espécies pequenas de aquários, podem ser mantidas em laboratório e expostas a substâncias químicas tóxicas. Além disso, peixes frequentemente respondem aos contaminantes de maneira similar a vertebrados superiores, podendo ser utilizados para rastrear substâncias químicas que apresentam potencial teratogênico ou cancerígeno em humanos. Sendo assim, o presente estudo corrobora com a importância de pesquisas ecotoxicológicas em bacias hidrográficas contaminadas por metais pesados, como apontado pela Agência Nacional de Águas no rio Uruguai. As análises da água apontaram concentração de cobre, no município de Uruguaiana, acima do recomendado pelo Conselho Nacional do Meio Ambiente. E o presente estudo apontou maior frequência de alterações nucleares em peixes expostos a esta concentração, indicando a potencialidade mutagênica da água deste rio, a qual é utilizada inclusive para abastecimento do município.

\section{Conclusões}

Com base nos resultados obtidos no estudo, foi verificado que a concentração de cobre do rio Uruguai $(0,08 \mathrm{mg} / \mathrm{L})$ aumentou somente a frequência dos micronúcleos, os quais são considerados danos mais graves em relação às demais alterações. As análises demonstraram que o período de $120 \mathrm{~h}$ já foi suficiente para aumentar consideravelmente o número de micronúcleos na espécie D. rerio, tanto em comparação com o grupo controle, quanto à concentração de $0,009 \mathrm{mg} / \mathrm{L}$, que é o máximo recomendado pela legislação brasileira.

Desta forma, pode-se comprovar a toxicidade desta concentração de cobre observada no rio, o que demonstra a gravidade do impacto gerado por este contaminante nas águas da bacia hidrográfica. Assim, os resultados encontrados neste trabalho servem como base para verificar a interferência da poluição deste recurso hídrico sobre os aspectos biológicos dos peixes que nele habitam, já que os organismos nele presentes estão sujeitos aos contaminantes por um período de exposição muito maior. O trabalho ainda busca fazer um alerta aos órgãos competentes para uma maior fiscalização dos produtos oriundos da pesca extrativa, os quais, apesar de expostos a diversos compostos em seus habitats, acabam sendo comercializados no município e região de forma direta para a população. 


\section{Agradecimentos}

Agradecemos ao Laboratório de Aquariofilia, Laboratório de Biologia e ao Laboratório do NUPILABRU (Núcleo de Pesquisas Ictiológicas, Limnológica e Aquicultura da Bacia do rio Uruguai), ambos do campus Uruguaiana da Universidade Federal do Pampa, pelo apoio com os materiais e equipamentos utilizados na realização desta pesquisa. Agradecemos também à instituição UNIPAMPA pelo apoio através da concessão de bolsa de iniciação científica.

\section{Referências}

AL-SABTI, K. \& METCALF, C.D. Fish micronuclei for assessing genetoxicity in water. Mutation Research, v. 343, Issues 2-3, p. 121-135, Jun. 1995.

ANA - Agência Nacional de Águas (Brasil). Panorama da qualidade das águas superficiais no Brasil. Brasília: ANA, 2005. (Estudo Técnico. Cadernos de Recursos Hídricos).

ANA - Agência Nacional de Águas (Brasil). Conjuntura de recursos hídricos no Brasil: 2011. Brasília: ANA, 2011a.

ANA - Agência Nacional de Águas (Brasil). Análise químico-física da água do rio Uruguai: 2011. ANA, 2011b. (Relatório Técnico).

ARINS, A. L. V. B. Bacias hidrográficas e aquíferos do Brasil. Estágio Curricular (Curso de Engenharia de Produção e Sistemas) - Universidade do Estado de Santa Catarina, Joinville, SC, 2010.

CARRASCO, R.K.; TILBURY, K.L.; MYERS, M. Assessment of piscine micronucleus test as an in situ biological indicator of chemical contaminant effects. Canadian Journal of Fisheries and Aquatic Sciences, v. 47, Issue 11, p.2123-2136, Apr. 1990.

EL-SHAHABY, A. O.; ABDEL, M. H. M.; SOLIMAN, M. I.; MASHALY I. A. Genotoxicity Screening of Industrial Wasterwater Using the Allium Cepa Chromosome Aberration Assay. Pakistan Journal of Biological Sciences, Baltimore, v. 6, Issue 1, p. 23-28, Dec. 2003.

GALVAN, G. L.; CESTARI, M. M., YAMAMOTO, C. I. Avaliação de genotoxicidade em eritrócitos de Astyanax altiparanae e Astyanax serratus (Pisces: Characidae) após exposição aguda ao sulfato de cobre. In: IX SIMPÓSIO DO PROGRAMA DE PÓS-GRADUAÇÃO EM ECOLOGIA E CONSERVAÇÃO, 2012, Curitiba. Livro de
Resumos... Curitiba: Universidade Federal do Paraná, 08 a 10 de agosto de 2012, p. 26.

HEDDLE, J.A., HITE, M., JRKHART, B., MACGREGOR, J.T., SALAMONE, M.F. The Indution of Micronuclei as a Measure of Genotoxicity. Mutation Research, v. 123, Issue 1, p. 61-118, Sep. 1983.

HOOFTMAN, R. N.; de RAAT, W. K. Induction of nuclear anomalies (micronuclei) in the peripheral blood erythrocytes of the eastern mudminnow Umbra pygmea by ethyl methanesulphonate. Mutation Research, Vol. 104, Issues 1-3, p.147-152, Apr. 1982.

LOMBARDI, J. V.; FERREIRA, C. M.; e RODRIGUES, E. L. Toxicologia Aquática. In: RANZANI PAIVA, M. J. T., TAKEMOTO, R. M., LIZAMA, M. A. P. Sanidade De Organismos Aquáticos. São Paulo: Editora Varela, 2004. p. 262-297.

MALUF, S.W., ERDTMANN, B. Biomonitorização do dano genético em humanos. In: SILVA, J., ERDTMANN, B., HENRIQUES, J.A.P. Genética Toxicológica. Porto Alegre: Editora Alcance, 2003. p. 181-205.

MARQUES, A.E.M.L. Comparação entre contagens de eritrócitos periféricos pelo teste de Micronúcleo Písceo em Astyanax fasciatus submetida à contaminação por sulfato de cobre. Monografia (Graduação em Ciências Biológicas) - Universidade Federal do Paraná, Setor de Ciências Biológicas, Curitiba, 2011.37p.

MMA - Ministério do Meio Ambiente. Resolução n ${ }^{0}$ 357 do CONAMA (Conselho Nacional do Meio Ambiente). Disponível em $<$ http://www.mma.gov. br/port/conama/res/res05/res35705.pdf $>$. Acesso em 24 maio 2013.

MONSERRAT, J.M., YUNES, J.S.; BIANCHINI, A. Effects of Anabaena spiroides (Cianobacteria) aqueous extracts on the acetylcholinesterase activity of aquatic species. Environmental Toxicology and Chemistry, v. 20, Issue 6, p. 12281235, Jun. 2001.

MULLER, A. C. Introdução à Ciência Ambiental. Curitiba - PUC - PR, uso didático. 2008. 98p.

OLIVEIRA, R. O peixe-zebra como uma ferramenta para avaliação de ecotoxicidade (Zebrafish early life-stages and adults as a tool for ecotoxicity assessment). Dissertação (Mestrado em Toxicologia e Ecotoxicologia) - Universidade de Aveiro, 
Departamento de Biologia, Portugal, 2009. 157p.

PIANCINI, L. D. S.; WILTEMBURG, F.; GRASSI, M.T.; CESTARI, M. M. Biomarcadores genéticos na avaliação do efeito genotóxico da atrazina e cloreto de cobre em Rhamdia quelen (Siluriformes, Heptapteridae). In: XII CONGRESSO BRASILEIRO DE ECOTOXICOLOGIA, 2012, Porto de Galinhas. Anais... Porto de Galinhas: Sociedade Brasileira de Ecotoxicologia (SBE), Universidade Federal de Pernambuco (UFPE), 25 a 28 de setembro de 2012.

SCHMID, W. The micronucleus test. Mutation Research, v. 31, Issue 1, p. 9-15, Feb. 1975. 